\title{
REMÉDIOS CONSTITUCIONAIS E SUA POPULARIZAÇÃO
}

Kayo Lucas Coutinho de Menezes, Shirley Oliveira Lima Nomura.

Universidade do Oeste Paulista- UNOESTE, curso de Direito, Presidente Prudente, SP. E-mail: kayomenezes77@gmail.com

\section{RESUMO}

Este artigo propõe-se a discutir sobre um tema fundamental no meio jurídico e social: os remédios constitucionais. Trazendo as ações em espécie e seu contexto histórico, com enfoque na importância destes direitos para o acesso real e efetivo a justiça. A falta de conhecimento da população sobre seus direitos fundamentais, mais especificamente os remédios constitucionais revelam uma barreira ao acesso a justiça e a efetivação de tais direitos. A mídia como veículo de informações pode ajudar a quebrar esta barreira, e construir um acesso mais rápido e fácil as informações formando cidadãos mais conscientes sobre seus direitos, garantias e deveres.

Palavras chaves: Remédios Constitucionais, Acesso à Justiça, Direitos fundamentais.

\section{CONSTITUTIONAL MEDICINES AND YOUR POPULARIZATION}

\section{ABSTRACT}

This article aims was discuss a fundamental issue in the legal and social environment: constitutional medicines. This article brings the actions in kind and their historical context, it's has focussed on the importance of these rights for real and effective access to justice. The lack of knowledge of the population about their fundamental rights, more specifically constitutional medicines, reveal a barrier to access to justice and the realization of such rights. The media as an information vehicle can help break this barrier, and build quicker and easier access to information by educating citizens more about their rights, guarantees and duties.

Keywords: Constitutional medicines, justice Access, rights fundamental. 


\section{INTRODUÇÃO}

Os direitos e garantias fundamentais estão previstos na constituição Federal brasileira, e Ihes cabe essa denominação por serem direitos essenciais para a sobrevivência humana, trazendo defesa, segurança e garantias para a população. Existem algumas ações que tem como dever a proteção de nossos direitos e são denominados remédios constitucionais, que em sua maioria estão previstos no artigo $5^{\circ}$ da Constituição Federal e consequentemente tem por natureza uma importância imensurável, pois estes exercem o papel de meios acessíveis a garantia de direitos previstos na lei máxima brasileira (PRADO, 2007).

Os direitos fundamentais nasceram como sendo aqueles considerados indispensáveis à pessoa humana, necessários para assegurar a todos uma existência digna, livre e igual, aí o porquê da denominação de fundamentais a tais direitos. (PRADO, 2007)

O nascimento dos direitos fundamentais está ligado diretamente como o movimento constitucionalista, selando o nascimento de garantias fundamentais através de uma lei máxima. Há, no entanto, uma grande divergência sobre qual o movimento que iniciou a primeira restrição ao poder estatal, sendo o movimento mais aceito e defendido pela doutrina tradicional, e pela maioria dos autores, é o movimento Magna Charta Libertatum, assinada pelo rei João Sem-Terra na Inglaterra em 1215. As ações constitucionais têm então como seu dever proteger, garantir ou efetivar um direito, Ihes são dadas a magnitude de fundamentais pelo fato de terem o seu embasamento na Constituição e serem acessíveis a todos (CALVALCANTE FILHO, 2017; PRADO, 2007).

Remédios constitucionais ou tutela constitucional é o nome dado a uma série de ações que estão a dispor da população, para que se tenha acesso a um direito supostamente cerceado ou a preste a ser, sanando ilegalidades ou abuso de poder. Os remédios constitucionais têm total embasamento na constituição de 1988, e no caso de algumas ações, em até constituições anteriores (BAHIA, 2014; CARVALHO, 2015).

Temos então o Habeas corpus (HC) que está previsto no artigo $5^{\circ}$ da Constituição Federal 1988, inciso LXVIII e teve a sua primeira aparição na constituição Brasileira em 1891, perdurando até a atual. Sua utilização está vinculada a proteção de direito líquido e certo, dividindo-se em preventivo que consiste na prevenção da violação da liberdade de locomoção e o repressivo que busca o cessar da violação de liberdade. O Habeas data (HD) por sua vez é previsto no artigo $5^{\circ}$ da Constituição Federal, inciso LXXII e tem sua garantia constitucional pela lei n. 9.507, de 12.11.1997, que assegura seu uso para o acesso a informações, que constam em registro ou banco de dados governamentais ou de caráter público ou a fim de modificação de dados (BRASIL, 1988; LENZA, 2012).

Já o Mandado de segurança (MS) está previsto no artigo $5^{\circ}$ da Constituição Federal, inciso LXIX e é uma ação constitucional que tem por sua natureza civil. Com o seu surgimento se coloca uma restrição na abrangência da "teoria brasileira do habeas corpus", ou seja, o que não cabe o uso de $\mathrm{HC}$ há o cabimento do uso do MS. O Mandado de segurança coletivo (MSC), se encontra no artigo $5^{\circ}$ da Constituição Federal, inciso LXX, que se diferencia na constituição de 1988 do mandado de segurança (individual) sobre os aspectos de objeto, e na legitimação ativa (quem pode impetrar) (BRASIL, 1988; LENZA, 2012).

Ação popular (AP) estabelece no Art. 5 LXXIII que qualquer cidadão é parte legítima para propor ação que vise a anular ato lesivo ao patrimônio público ou de entidade de que o Estado participe, à moralidade administrativa, ao meio ambiente e ao patrimônio histórico e cultural, tendo como sua finalidade a proteção dos interesses difusos. O Mandado de injunção (MI) tem sua previsão no Art. 5ㅇ, inciso LXXI da Constituição de 1988, e tem como os seus requisitos para a sua utilização, normas constitucionais de eficácia limitada como o olhar sobre direitos, liberdades constitucionais e também prerrogativas sobre a nacionalidade, à soberania, e à cidadania (BRASIL, 1988; LENZA, 2012). 
Este trabalho tem por principal objetivo discutir sobre os remédios constitucionais com enfoque na importância desses direitos para o acesso real e efetivo à justiça, assim como estabelecer uma relação entre a população e seu conhecimento sobre o assunto com o acesso à justiça.

\section{METODOLOGIA}

A plataforma eletrônica de formulários do Google ${ }^{\circledR}$ foi utilizada para levantamento de dados sobre o conhecimento da população por meio de perguntas sobre o tema. $O \mathrm{n}=100$ de pessoas responderam ao questionário de forma anônima. Os entrevistados responderam um total de seis perguntas, sendo os dados processados pela própria plataforma em forma de gráficos.

\section{RESULTADOS}

A maior parte da população demonstrou desconhecer sobre a existência dos remédios constitucionais (GRAFICO 1), não sabendo sobre o que eles tratam nem como eles asseguram direitos fundamentais ao cidadão.

Gráfico 1. Conhecimento sobre o que são remédios constitucionais.

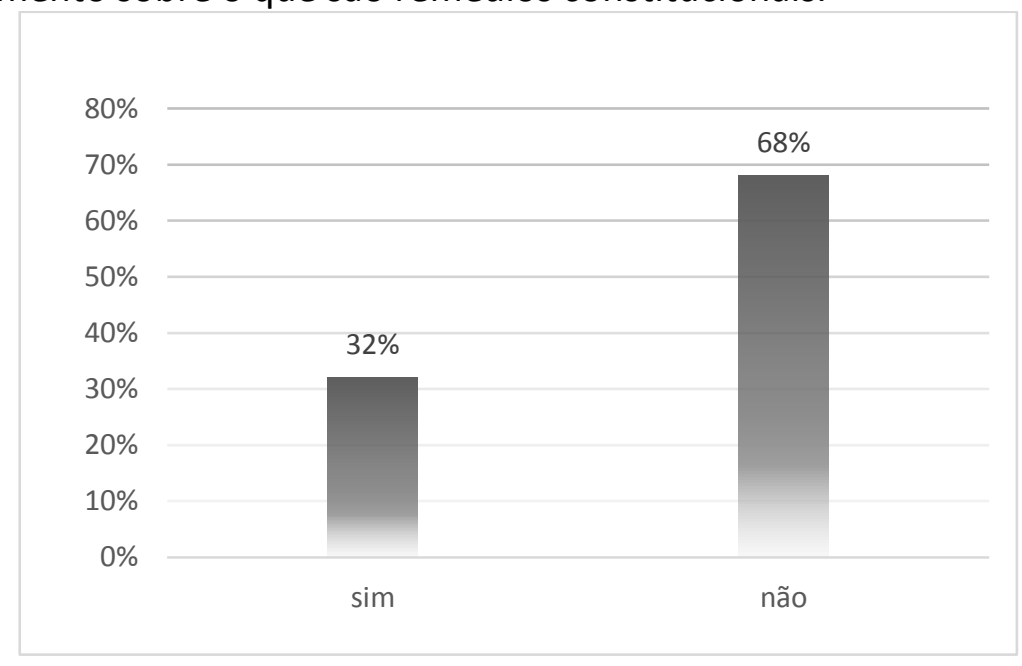

Quando questionado sobre dois tipos de ações (o habeas corpus e Habeas data), que são pertencentes aos remédios constitucionais, o HC é apontado com maior frequência como sendo algo de maior conhecimento da população em relação ao Habeas data (TABELA 1).

Tabela 1. Conhecimento da população leiga sobre dois tipos de remédios constitucionais

\begin{tabular}{lll}
\hline Tipo de Remédio constitucional & Sim & Não \\
\hline Habeas Data & $39 \%$ & $61 \%$ \\
Habeas corpus & $70 \%$ & $30 \%$ \\
\hline
\end{tabular}

Observou-se também que a renda não influência sobre o a ciência da população acerca dos remédios constitucionais (TABELA 2) 
Tabela 2. Relação entre a renda e o conhecimento acerca sobre o que são remédios constitucionais entre os entrevistados

\begin{tabular}{|c|c|c|}
\hline \multicolumn{3}{|c|}{$\begin{array}{l}\text { Relação entre a renda e conhecimento sobre o que são Remédios } \\
\text { constitucionais }\end{array}$} \\
\hline Renda (R\$) & Sim & Não \\
\hline 0 a 900 & $9 \%$ & $17 \%$ \\
\hline 901 a 1800 & $8 \%$ & $26 \%$ \\
\hline 1801 a 2700 & $7 \%$ & $9 \%$ \\
\hline Acima de 2700 & $9 \%$ & $16 \%$ \\
\hline Total & $32 \%$ & $68 \%$ \\
\hline
\end{tabular}

\section{DISCUSSÃO}

$\mathrm{Na}$ contemporaneidade com a facilidade do trânsito e o exacerbado volume de informações que recebemos e processamos todos os dias, a qualidade do que chega até nós é pouco questionada, uma vez que processamos sem ao menos parar e refletir sobre o conteúdo veiculado; tem-se deixado de lado cada vez mais, com o avanço dos meios de comunicação o princípio básico da reflexão e discussão de ideias e informações, tornando a população cada vez mais alienada e desinformada apesar do grande número de informação que a mesma recebe.

As informações sobre os direitos também está se adaptando com a evolução desses meios, e hoje se tem maior facilidade para se ter acesso a informação graças a internet, mas infelizmente muitos dos veículos de comunicação não passam corretamente ou destorcem a real informação sobre os direitos.

Isto também é valido para os remédios constitucionais, que por sua vez tem o HC mais especificamente sendo constantemente citado em novelas, publicações em sites de comédia e entre outros veículos de comunicação. No entanto apesar disso, pouco se sabe sobre o que se tratam esses direitos, o que leva a uma barreira conhecida pelos juristas como a barreira ao acesso à justiça.

Os dados encontrados demonstram e apontam para a possível influência dos meios de comunicação sobre a formação do conhecimento da população em geral. Segundo POMPEIO e MARTINI, (2012), a mídia como a formadora de opinião que é, presta serviço de ordem social, público e essencial a sociedade, exercendo o papel de difusora do conhecimento, sendo assim é um meio de extrema importância para sanar o déficit em relação ao conhecimento, e acabar com a desigualdade ao veicular informações, principalmente sobre os direitos para todos.

O sentido de acesso à justiça não se limita a questão de assistência jurídica gratuita a quem necessita, quando se fala em acesso à justiça se deve pensar e falar em garantia universal de defesa de todo e qualquer direito, independe de classe social, etnia ou nível de escolaridade (CAPPELLETTI e GARTH, 1988; ARAÚJO, 2010).

"O acesso à justiça pode, portanto, ser encarado como o requisito fundamental - o mais básico dos direitos humanos - de um sistema jurídico moderno e igualitário que pretende garantir, e não apenas proclamar os direitos de todos" (CAPPELLETTI e GARTH, 1988, p.12).

O problema em relação ao acesso a justiça e assim consequentemente o acesso a informação sobre os remédios constitucionais, tem inúmeros fatores como entrave; um deles, se não o principal, é o planejamento educacional onde as crianças deveriam ter uma instrução sobre os direitos desde o começo, ainda na escola, progredindo assim no nível educacional do país e futuramente os tornando-os cidadãos conhecedores de seus direitos e deveres. Observa-se que o fator renda não influencia sobre o acesso à informação visto que as variações entre o conhecimento nas diferentes faixas de renda não apresentam grandes diferenças entre a maior e 
a menor faixa renda quando comparadas entre si (ATHAYDE \& ADVOGADOS ASSOCIADOS, 2016; NASCIMENTO, 2010).

Para que haja um acesso à justiça de modo efetivo e como resultado a dominação dos remédios constitucionais, se deve ter maior acessibilidade primeiramente a informação para a população, onde os membros de um Estado tenham consciência e pleno gozo de seus direitos, a aposta está nas gerações futuras, mas se faz necessário dar o primeiro passo hoje para a garantia do amanhã.

\section{CONCLUSÃO}

Os remédios constitucionais é um tema complexo e muito rico, sobre o qual pouco se conhece, e pouco se discute, evidenciado pela falta de ciência da população sobre estes direitos, delimitando assim uma grande barreira ao acesso real e efetivo a justiça. Concluímos então que, apesar de serem direitos fundamentais e algo de extrema importância, os remédios constitucionais ainda é um tema que se encontra restrito as salas de aula em universidade de direito e entre os juristas, expondo a população a inercia sobre seus direitos permitindo que estes sejam violados. A falta de acesso a informação neste caso configura um dos maiores entraves aos direitos fundamentais; cenário que poderia ser revertido pela introdução deste tipo de informação através das escolas e mídias.

\section{REFERÊNCIAS}

ARAÚJO, T.C. P. Acesso à justiça e a efetividade do processo. TEMA-Revista Eletrônica de Ciências (ISSN 2175-9553), v. 8, n. 12, 2009. Disponível em: <http://revistatema.facisa.edu.br/index.php/revistatema/article/view/17/37>. Acesso em 16 de jun. de 2018.

ATHAYDE \& ADVOGADOS ASSOCIADOS. A falta de conhecimento e o acesso à justiça, 2016. Disponível em: <http://athayde.com.br/a-falta-de-conhecimento-e-o-acesso-a-justica-2/>. Acesso em 15 de jul.de 2018.

BAHIA, F. OAB segunda fase direito constitucional. e. Juspodivm. 2014.

BRASIL. Constituição (1988). Constituição da República Federativa do Brasil. Brasília, DF: Senado Federal: Centro Gráfico, 1988.

CAPPELLETTI, M.; GARTH, B. Acesso à Justiça. Tradução de Ellen Gracie Northfleet. Porto Alegre: ed. Sérgio Antonio Fabris, 1988.

CARVALHO, G.O. Remédios constitucionais, Direito net, 2015. Disponível em: <https://www.direitonet.com.br/artigos/exibir/9475/Remedios-constitucionais>. Acesso em 04 de jul.de 2018.

CAVALCANTE FILHO, J.T. Teoria Geral dos Direitos Fundamentais. v. 13, 2017. Disponível em: <http://www.stf.jus.br/repositorio/cms/portaltvjustica/portaltvjusticanoticia/anexo/joao_trindad ade_teoria_geral_dos_direitos_fundamentais.pdf>. Acesso em 10 de jul.de 2018.

LENZA, P. Direito constitucional esquematizado. 20.ed. Rev. Atual. Ampl. São Paulo, método, 2012.

NASCIMENTO, M.S. Acesso à justiça: abismo, população e judiciário. In: Âmbito jurídico, Rio Grande, XIII, n. 74, mar 2010. Disponível em: <http://www.ambito- 
juridico.com.br/site/index.php?n_link=revista_artigos_leitura\&artigo_id=7498>. Acesso em 15 de jul.de 2018.

POMPÉO, W. A. H.; MARTINI, A.J. O papel da mídia na construção da democracia, cidadania e justiça no mundo globalizado: um estudo voltado aos efeitos das ações de imprensa e micropoliticas fundadas no espaço local. In: Congresso Internacional de Direito e Contemporaneidade. 2012.

PRADO, J.C.N.A. Direitos Fundamentais: direito de todos? O dever ético constitucional e a reserva do possível. Revista Brasileira de Direito Constitucional-RBDC, São Paulo, n. 10, p. 259-294, jul/dez. 2007. Disponível em: <http://www.esdc.com.br/seer/index.php/rbdc/article/view/212/205>. Acesso em 08 de jul.de 2018. 